\title{
SHARP INEQUALITIES INVOLVING NEUMAN-SÁNDOR AND LOGARITHMIC MEANS
}

\author{
EDWARD NEUMAN
}

Abstract. Sharp bounds for the Neuman-Sándor mean and for the logarithmic mean are established. The bounding quantities are the one-parameter bivariate means called the p-means. In this paper best values of the parameters of the bounding means are obtained.

Mathematics subject classification (2010): 26E60, 26D07, 26D20.

Keywords and phrases: Neuman-Sándor mean, logarithmic mean, p-means, inequalities.

\section{REFERENCES}

[1] J. M. Borwein, P. B. Borwein, Pi and AGM: A Study in Analytic Number Theory and Computational Complexity, John Wiley and Sons, New York, 1987.

[2] B. C. CARLson, Algorithms involving arithmetic and geometric means, Amer. Math. Monthly 78 (1971), 496-505.

[3] Y.-M. CHU, S.-W. Hou, Z.-H. SHEN, Sharp bounds for Seiffert mean in terms of root mean square, J. Inequal. Appl. 2012, 11 (2012), 15 pages.

[4] Y.-M. ChU, M.-K. WANG, Z.-K. WANG, A best possible double inequality between Seiffert and harmonic means, J. Inequal. Appl. 2011, 94 (2011), 7 pages.

[5] Y.-M. LI, B.-Y. Long, Y.-M. CHU, Sharp bounds for the Neuman-Sándor mean in terms of generalized logarithmic mean, J. Math. Inequal. 4, 4 (2012), 567-577.

[6] D. S. Mitrinović, Analytic Inequalities, Springer-Verlag, Berlin, 1970.

[7] E. Neuman, Inequalities for the Schwab-Borchardt mean and their applications, J. Math. Inequal. 5, 4 (2011), 601-609.

[8] E. Neuman, A note on a certain bivariate mean, J. Math. Inequal. 4 (2012), 637-643.

[9] E. Neuman, Inequalities for weighted sums of powers and their applications, Math. Inequal. Appl. 15, 4 (2012), 995-1005.

[10] E. Neuman, A one-parameter family of bivariate means, J. Math. Inequal., in press.

[11] E. Neuman, J. SÁndor, On the Schwab-Borchardt mean, Math. Pannon. 14 (2003), 253-266.

[12] E. Neuman, J. SÁndor, On the Schwab-Borchardt mean II, Math. Pannon. 17 (2006), 49-59.

[13] M.-K. WANG, Y.-M. ChU, B.-Y. LiU, Sharp inequalities for the Neuman-Sándor mean in terms of arithmetic and contra-harmonic means, preperint, arXiv: 1209.5825 vol 1 [math CA] 26 Sep. 2012.

[14] T.-H. ZhaO, Y.-M. ChU, B.-Y. LiU, Optimal bounds for the Neuman-Sándor mean in terms of the convex combinations of harmonic, geometric, quadratic and contra-harmonic means, Abstract Appl. Anal. Volume 2012, Article ID 302635, 9 pages. 